\section{Pterodactyl habits - real and radio-controlled}

SIR-Following in part new work by others ${ }^{1,2}$, Unwin ${ }^{3}$ has suggested that the pterosaur's ability to move on the ground was very limited. This contradicts arguments that pterosaurs were terrestrial, erect-limbed bipeds ${ }^{4}$. Pterosaur anatomy and lifestyles show a diverse pattern of running and climbing adaptations.

It has recently been shown that in some pterosaurs the lower hip elements were splayed apart, and that the acetabulem faced to the side or a little up ${ }^{3}$. Unwin believes this means that they had sprawling, "clumsy" legs. But sprawling lizards and certain bats are quite agile, and erect birds also have widely separated lower hip elements and side-facing hip sockets. The sharply inturned, bird-like femoral head of the early pterosaur Dimorphodon worked in an erect plane, with the knee only moderately bowed out. In more advanced pterosaurs less offset, more spherical femoral heads indicate that they had reverted to more supple, semi-erect legs. Trackway gauge probably remained narrow because the knee was sharply flexed postero-medially. It is emphasized that the pterosaur's avian-style knee, shank and ankle were too stiff to follow the twisting motions of a truly sprawling gait. Nor did any pterosaur have reduced swift- or frigate bird-like legs that would have made them incompetent on the ground.

Quetzalcoatlus firmly establishes that pterosaurs were fast and agile on the ground. This giant lived on a flat floodplain $400 \mathrm{~km}$ from the palaeocoastline 5 . Restorations I helped draw up for a scale flapping flight model ${ }^{6}$ indicate that Quetzalcoatlus was 10 feet tall and massed perhaps 250 pounds; too large to roost in trees, pursue aerial prey, or to snap up fish from its habitat's limited watercourses while on the wing. Carcass scavenging was not possible either because the crane-like beak was much too weak, and even Marabou storks use their much stouter beaks only to pick up scraps dropped by vultures'. Instead, Quetzalcoatlus probably picked up fish, frogs, turtles and so on from the shallows. On windless days it had to take off with an $\sim 30 \mathrm{~km} \mathrm{~h}^{-1}$ run. The dense bristle-toothed jaws of smaller filter feeders such as Pterodaustro could also only be swished through the water as they waded.

As for how pterosaurs walked, flexing the elbow $90^{\circ}$ downwards allowed their arms to work in a narrow gauge mode. Long-tailed rhamphorhynchoids could have been both two and four legged, except for Dimorphodon whose upper arm and hand were too short relative to the hindlimb for quadrupedalism. I agree with Pennycuick ${ }^{2}$ that the tailless pterydactyloids lacked the adaptations for full bipedalism found in tailless birds - they were more quadrupedal.

Impressions show that the wing membrane's trailing edge attached to the body ${ }^{4}$, or to the thigh ${ }^{1}$, although these may be partly folded membranes overlapping the thighs. The rhamphorhynchoid's long, rudder-tipped tail acted as an auxiliary control surface. Tailless pterodactyloids may have evolved their more supple legs in order to manipulate a hip-to-ankle membrane. Folded for streamlining during cruising flight, it could have deployed into an inverted- $V$ shaped tail surface for landings, for instance. Traces of such a uropatigium appear to be preserved in two Pterodactylus specimens ${ }^{1.8}$, despite Wellnhofer's arguments to the contrary.

As shown by squirrels, cats, and many birds, running and climbing are not mutually exclusive adaptations. Small pterosaurs were probably good at both, and the long, divergent outer toe of rhamphorynchoids may have enhanced the grasping ability of their feet. However, the rhamphorynchoid's long, ossified-rod stiffened tails could not fold tightly enough to be out of harm's way if their owners hung from branches by their hindfeet ${ }^{3}$.

Gregory S. Paul

3109 N. Calvert Street,

Baltimore, Maryland 21218, USA

1. Wellnhofer, P. A. Naturhist. Mus. Wien 88, 149-162 (1987)

2. Pennycuick, C. J. Mem. Calif. Acad. Sci. 8, 83-98 (1986)

3. Unwin, D. M. Nature 527, 13-14 (1987).

4. Padian, K. Paleobiology 9, 218-239(1983)

5. Lawson, D A Science 187 947-948.

6. MacCready, P. Engineer. Sci. XLIX (2), 18-24 (1985)

7 . Houstan D. C. in Serengeti; Dynamics of an Ecosystem 263-286 (University of Chicago Press, 1979)

8. Broili, F. Sitzungber. Bayer. Akad. Wiss, math. naturwiss., 139-154 (1938)

\section{Of fast teeth and big heads}

SIR-Beynon and Wood interpret their important data on early hominid molar growth ${ }^{1}$ to suggest that hominid growth two million years ago was 'more rapid' than that for modern teeth: "The absolutely shorter growing period of these larger molar crowns suggests that there was strong selection to form teeth quickly and have them erupted into the mouth early in development." There is a confounding problem of anthropocentricism here - and a common fallacy of adaptationist thinking in cases of pleiotropy.

Comparisons of the duration of life span phases in primates suggest that developmental rates have been slowed between monkey and ape, and slowed again between ape and modern humans; it is probably not a matter of 'why they were fast' but of 'why we are so slow'.

For our slowing, a proximate cause is not hard to find, given a tendency toward juvenilization (besides the flatter faces of later adult hominids, the progressivelyreduced crown surface area of mandibular cheek teeth ${ }^{2}$ is also consistent with retention of juvenile features). Precocious puberty does make heads relatively larger, compared to pelvic outlets, causing problems in subsequent generations. Given that a fetus with a big head kills not only itself but its mother and thereby other siblings, it is hard to imagine a more serious 'genetic disease' than big heads; the resulting selection against average and faster-than-average developmental rate variants must have been severe, with only slower-than-average variants surviving to raise children ${ }^{3}$.

Although the selection pressures on slowing might have been solely associated with slowed fetal development to hold down head size until the end of standard gestation, slower somatic development probably carried over to later life as well, since later developmental landmarks also suggest slowing ${ }^{4}$. Such 'birth canal bottleneck' selection favouring slowed development is far removed from 'strong selection to form teeth quickly'. Where there is pleiotropy - overall developmental rates are a prime example of diverse body features controlled by a common set of genes - cause and effect are sometimes linked by long indirect paths that confound straightforward adaptationist reasoning.

University of Washington,

William H. Calvin

Biology Program, NJ-15

Seattle, Washington 98195, USA

Beynon, A.D. \& Wood, B.A. Nature 326, $493-496$ (1987) Isaac, G. Ll. in Evolution from Molecules to Men (ed. Bendall, D.S.) 528 (Cambridge University Press, 1983).

. W.H. Calvin The River That Flows Uphill: A Journey from the Big Bang to the Big Brain. (Macmillan, New York, 1986)

Harvey, P. H. \& Clutton-Brock, T . H. Evolution 39, 559-581 (1985). 